OPEN ACCESS

Edited by:

Ricardo Rocha

University of Cambridge,

United Kingdom

Reviewed by:

David López-Bosch,

Granollers Museum of Natural

Sciences, Spain

Bruce D. Patterson,

Field Museum of Natural History,

United States

*Correspondence:

Thomas M. Lilley

thomas.lilley@helsinki.fi

Specialty section:

This article was submitted to

Conservation and Restoration

Ecology,

a section of the journal

Frontiers in Ecology and Evolution

Received: 25 November 2021

Accepted: 26 January 2022

Published: 17 February 2022

Citation:

Meramo K, Ovaskainen O, Bernard E, Silva CR, Laine VN and Lilley TM (2022) Contrasting Effects

of Chronic Anthropogenic

Disturbance on Activity and Species

Richness of Insectivorous Bats

in Neotropical Dry Forest.

Front. Ecol. Evol. 10:822415.

doi: 10.3389/fevo.2022.822415

\section{Contrasting Effects of Chronic Anthropogenic Disturbance on Activity and Species Richness of Insectivorous Bats in Neotropical Dry Forest}

\author{
Katarina Meramo ${ }^{1}$, Otso Ovaskainen ${ }^{2,3,4}$, Enrico Bernard ${ }^{5}$, Carina Rodrigues Silva ${ }^{5,6}$, \\ Veronika N. Laine ${ }^{1}$ and Thomas M. Lilley ${ }^{1 *}$ \\ ${ }^{1}$ Finnish Museum of Natural History, University of Helsinki, Helsinki, Finland, ${ }^{2}$ Department of Biological and Environmental \\ Science, University of Jyväskylä, Jyväskylä, Finland, ${ }^{3}$ Organismal and Evolutionary Biology Research Program, Faculty of \\ Biological and Environmental Sciences, University of Helsinki, Helsinki, Finland, ${ }^{4}$ Department of Biology, Center \\ for Biodiversity Dynamics, Norwegian University of Science and Technology, Trondheim, Norway, ${ }^{5}$ Laboratório de Ciência \\ Aplicada à Conservação da Biodiversidade, Departamento de Zoologia, Universidade Federal de Pernambuco, Recife, \\ Brazil, ${ }^{6}$ Programa de Pós-graduação em Biologia Animal, Universidade Federal de Pernambuco, Recife, Brazil
}

For prioritizing conservation actions, it is vital to understand how ecologically diverse species respond to environmental change caused by human activity. This is particularly necessary considering that chronic human disturbance is a threat to biodiversity worldwide. Depending on how species tolerate and adapt to such disturbance, ecological integrity and ecosystem services will be more or less affected. Bats are a species-rich and functionally diverse group, with important roles in ecosystems, and are therefore recognized as a good model group for assessing the impact of environmental change. Their populations have decreased in several regions, especially in the tropics, and are threatened by increasing human disturbance. Using passive acoustic monitoring, we assessed how the species-rich aerial insectivorous batsessential for insect suppression services-respond to chronic human disturbance in the Caatinga dry forests of Brazil, an area potentially harboring ca. 100 bat species (nearly 50\% are insectivorous), but with > 60\% its area composed of anthropogenic ecosystems under chronic pressure. Acoustic data for bat activity was collected at research sites with varying amounts of chronic human disturbance (e.g., livestock grazing and firewood gathering). The intensity of the disturbance is indicated by the global multi-metric CAD index (GMDI). Using Animal Sound Identifier (ASI) software, we identified 18 different bat taxon units. Using Hierarchical Modeling of Species Communities (HMSC), we found trends in the association of the disturbance gradient with species richness and bat activity: species richness was higher at sites with higher human disturbance, whereas bat activity decreased with increasing human disturbance. Additionally, we observed taxon-specific responses to human disturbance. We conclude 
that the effects of chronic anthropogenic disturbance on the insectivorous bat fauna in the Caatinga are not homogeneous and a species-specific approach is necessary when assessing the responses of local bats to human disturbances in tropical dry forests, and in other biomes under human pressure.

Keywords: human disturbance, biodiversity loss, Chiroptera, passive acoustic monitoring, tropical dry forests, echolocation, Caatinga, HMSC

\section{INTRODUCTION}

Human activity is responsible for the most significant threats to biodiversity, including habitat degradation and excessive use of natural resources [World Wide Fund for Nature [WWF], 2018]. To facilitate conservation of global biodiversity, it is vital to understand how ecologically diverse species cope with environmental change caused by anthropogenic disturbance. An increasing human population puts pressure on pristine habitats, mainly through agricultural expansion and urbanization (Ellis and Ramankutty, 2008). Some taxa are able to adapt to modified environments where they can utilize human-based resources, such as artificial food or man-made structures (Prange et al., 2004; Ávila-Flores and Fenton, 2005). Other species, however, are not found in disturbed areas as they depend on food, shelter and habitats that only natural sites can sufficiently offer (Mckinney, 2009). Information on the ecological needs of individual species is required to predict the risks of local extinction and to propose adequate conservation strategies in an increasingly impacted world.

With over 1,400 species distributed globally, bats make up the second largest mammalian order and provide key ecosystem services as seed dispersers (Villalobos-Chaves and RodríguezHerrera, 2021), pollinators (Cordero-Schmidt et al., 2021), and pest suppressors (Aizpurua et al., 2018; Vesterinen et al., 2018; Ramírez-Fráncel et al., 2021; Maslo et al., 2022). Despite the fact that the economy largely benefits from services provided by bats (Wanger et al., 2014; Rodríguez-San Pedro et al., 2020; Aguiar et al., 2021), they are highly susceptible to human activity (Voigt and Kingston, 2015; Frick et al., 2019). Indeed, 21\% of species are considered endangered or near threatened (IUCN), and globally every four out of five bat populations are decreasing (Welch and Beaulieu, 2018). Bat diversity peaks in tropical regions (Kaufman, 1995; Mickleburgh et al., 2002; Stevens, 2004). However, these habitats are rapidly being degraded and converted to other purposes, which has negative consequences on bat populations (García-Morales et al., 2013; Meyer et al., 2016; Frick et al., 2019; Núñez et al., 2019). Bat ecological research and conservation efforts in Neotropical forests have documented shifts in bat population dynamics and diversity as a result of land-use changes, habitat loss and fragmentation (Medellín et al., 2000; Bernard and Fenton, 2002; Meyer and Kalko, 2008; EstradaVillegas et al., 2012; de la Peña-Cuéllar et al., 2015; Núñez et al., 2019). Taking into account their high species richness, bats can be considered a good model group for studies on the impact of human disturbance, such as landscape changes (Jones et al., 2009; Park, 2015; Russo et al., 2021). However, insectivorous bat fauna is typically underrepresented in most studies in Neotropics because bat inventories have been mostly conducted using mistnet sampling and roost search instead of using bioacoustic approaches (Sampaio et al., 2003; Arias-Aguilar et al., 2018).

The magnitude and direction of anthropogenic effects on Neotropical bat communities depends on the type of disturbance (García-Morales et al., 2013). Several studies report that the number of bat species declines with increasing vegetation disturbance (Medellín et al., 2000; Bernard and Fenton, 2002; Estrada and Coates, 2002), whereas others report that disturbance does not affect bats (Clarke et al., 2005; Pineda et al., 2005), or may even increase the species richness (Vargas et al., 2008). However, these responses are known to vary between different bat taxa, and these differences may be due, for example, to different habitat use that can be indicated by wing morphology or echolocation traits (Marinello and Bernard, 2014; Núñez et al., 2019). For instance, molossids (Molossidae) are known to tolerate urbanization and agricultural expansion (Jung and Kalko, 2011; Rodríguez-Aguilar et al., 2017) whereas Myotis species, are known to be more sensitive to humaninduced changes (Rodríguez-Aguilar et al., 2017). Additionally, most of the studies focus on cases where anthropogenic pressure results in complete removal and destruction of natural habitats, decreasing forest cover worldwide with acute negative impacts on tropical biodiversity's biological integrity (GarcíaMorales et al., 2013; Meyer et al., 2016). On the other hand, anthropogenic disturbances are often chronic, causing relatively weak but continuous impact. Some studies have shown these chronic anthropogenic disturbances may also strongly affect species richness and composition, functional and phylogenetic diversities, ecological processes, and ecosystem services (Leal et al., 2014; Ribeiro et al., 2015, 2016). Moreover, chronic human disturbance poses a legal challenge in megadiverse regions, because the livelihood of the inhabitants frequently depend to some extent on forest products.

In the Brazilian Caatinga, anthropogenic disturbances are mostly chronic. The Caatinga is a Neotropical xeric shrubland and thorn forest with an uneven and low precipitation, generally appearing as a short, irregular wet season between April and August (Rocha et al., 2015). It is one of the world's most species-rich dry forests with one of the highest degree of floristic endemism in the world (Silva et al., 2017), but it is threatened by human-driven habitat changes (Queiroz et al., 2017). With over 23 million people ( $\sim 12 \%$ of the Brazil's population; 23 inhabitants per $\mathrm{km}^{2}$ ), the Caatinga is affected by strong chronic anthropogenic disturbance. In recent decades, more than half of the Caatinga area has been converted by agriculture and livestock production, leading to a significant loss of its natural vegetation. More than $65 \%$ of the area is already impacted, and only $0.5 \%$ 
is formally protected (Silva et al., 2018). Understanding how the Caatinga's rich biota respond to such impacts is considered priority for the conservation of this large biome (PortilloQuintero et al., 2015). Approximately 1,400 vertebrate species occur in the Caatinga, 183 of which are mammals (Garda et al., 2018). Bats account for $>50 \%$ of that, with at least 96 species including two endemic and four nationally threatened species (Silva et al., 2018). The Caatinga also has areas harboring caves, which are important roosting sites for large populations of several bat species (Delgado-Jaramillo et al., 2018; Otálora-Ardila et al., 2020). Given the widespread threat to the conservation of the Brazilian Caatinga represented by intensive cultivation and grazing from livestock, the assessment of the effects of anthropogenic changes on the structure of bat assemblages may produce practical results useful for conservation and restoration.

Our overall aim is to investigate the impact of varying amounts of chronic human disturbance (e.g., livestock grazing and firewood gathering) on insectivorous bat species assemblages in Brazil's Caatinga dry forests. We focus on the chronic disturbance measured by the global multi-metric CAD index (GMDI), especially generated for arid and vulnerable environments (Arnan et al., 2018). Bat taxa are identified from passive acoustic monitoring data using machine learning software that performs probabilistic classification of species occurrences [Animal Sound Identifier (ASI); Ovaskainen et al., 2018] and their responses to environmental covariates are analyzed with an analytical framework including hierarchical layering (Abrego et al., 2017; Ovaskainen et al., 2017). These methods are employed in particular to look at whether there are differences between insectivorous taxa in their responses to human disturbance and whether seasonal variation affects bat activity and species assemblage. We predict that human disturbance has mixed impacts on bat communities, both on species richness and activity. We further predict that within the insectivorous bat community, molossids (Molossidae) show more activity in human-impacted habitats compared to less disturbed habitats (Jung and Kalko, 2011; Marinello and Bernard, 2014) whereas the response in Myotis species is contrasting (Marinello and Bernard, 2014; Rodríguez-Aguilar et al., 2017; Dietz et al., 2020).

\section{MATERIALS AND METHODS}

\section{Study Location}

The study was conducted in Catimbau National Park $\left(08^{\circ} 32^{\prime} 54^{\prime \prime}\right.$ S; $\left.37^{\circ} 14^{\prime} 49^{\prime \prime} \mathrm{W}\right)$, located in the central of Pernambuco state (Figure 1). The park has a total area of 62,294 ha with altitudes between 370 and 1,068 $\mathrm{m}$ (Cavalcanti and Corrêa, 2014). The climate is semi-arid tropical, with a mean annual temperature of $23^{\circ} \mathrm{C}$ and rainfall between 300 and $500 \mathrm{~mm} /$ year (Geise et al., 2010). The typical vegetation of Caatinga is deciduous or subdeciduous xerophytic shrub, perennial herbaceous (DrechslerSantos et al., 2010) and arboreal-shrubby (Geise et al., 2010) on rock fields and sandy soil. The national park was established in 2002 , but human inhabitants remain in the area. Their historical presence has resulted in an extensive land use and anthropogenic pressure on the local biota, but without acute disturbances affecting the biota in recent decades (Arnan et al., 2018). Thus Catimbau represents an excellent opportunity for examining how chronic anthropogenic disturbance affects the biota of the Caatinga. The main land use activities in Catimbau region are small-scale, free-roaming livestock (goats and cattle) ranching, small-scale timber extraction, firewood collection, hunting, and harvesting of medicinal plants (Rito et al., 2017). Together, they have a continuous effect varying from a relatively small decrease in biomass to severe degradation (Ribeiro et al., 2015).

\section{Study Design and Sampling Protocol}

A long-term ecological project ${ }^{1}$ established 20 plots along different disturbance gradients in Catimbau National Park. We recorded bats simultaneously in 13 of those plots (Figure 1), separated by at least $2 \mathrm{~km}$ each, and with the chronic disturbance index GMDI (Please see the section "The disturbance index GMDI") ranging from 9 to 58. We used AudioMoth ${ }^{2}$ passive recorders for our acoustic survey. We placed one device in each plot $1.5 \mathrm{~m}$ above ground pointing toward an open space to record from 17:15 to $05: 15 \mathrm{~h}$. Recorders were active 15 min twice within each hour, at a sample rate of $384 \mathrm{kHz}$ and medium gain level $(30.6 \mathrm{~dB})$. This schedule was adopted to save space on memory cards. We repeated this scheme on three consecutive nights on three different research visits (4th-8th of September 2018, 27th September-1st October 2018 and 18th-22nd of December 2018) in the national park. No rainfall was documented on any of the sampling nights. Moon phase or wind was not documented.

\section{The Disturbance Index Global Multi-Metric CAD Index}

We used the global multi-metric disturbance index-GMDI, developed for the Caatinga region by Arnan et al. (2018). To calculate chronic anthropogenic disturbance indices Arnan et al. (2018) first used 12 variables representing three different categories: the "Geographic context" (the distances to a village, houses and roads), the "Social-ecological context" (the number of people, goats and cattle, and the use of firewood), and the "Local scale" (the length of goat trails, the amount of goat and cattle dung, wood extraction, firewood collection). Based on variables from those 12 primary sources, they constructed three singledisturbance pressure indices: (1) livestock pressure index, (2) wood extraction index and (3) people pressure index (Please see Supplementary Table 1 for the values at our study sites). Finally, these single disturbance pressure indices were combined into a fully integrated, multi-metric index that characterizes the overall level of CAD (chronic anthropogenic disturbance), creating the conceptual framework for the Global multi-metric CAD index (GMDI). The overall GMDI theoretically ranges from 0 (lowest) to 100 (highest level of disturbance), however, the highest value of the original study system is 59.07 . GMDI is targeted to identify the main sources of chronic disturbance in the target region. This conceptual framework is of particular relevance to arid and semiarid areas of developing countries, especially where people are highly dependent on the extraction of a wide range of natural

\footnotetext{
${ }^{1}$ www.peldcatimbau.org

${ }^{2}$ https://www.openacousticdevices.info/
} 


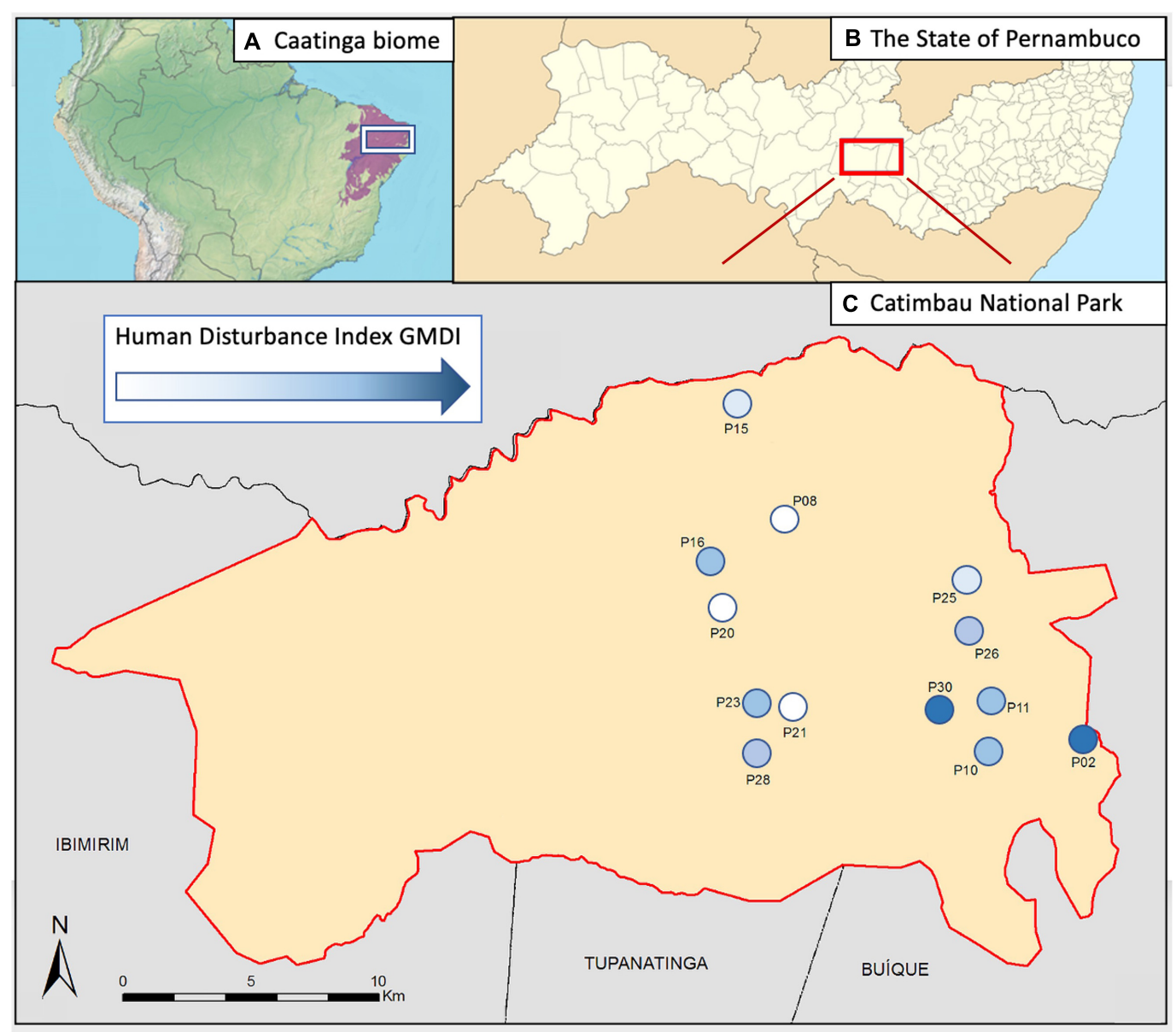

FIGURE 1 | (A) The region of the Caatinga (violet) and the location of the study region (within the white box), (B) Catimbau National Park (red box; within Pernambuco), and (C) the research sites (numbered circles; within Catimbau National Park). The color of numbered circles depicts the intensity of anthropogenic disturbance with the scale of the disturbance index GMDI, white indicating the least disturbance, dark blue the most disturbance, and the range in our study varies from 9 to 58 .

resources. For a full description see Arnan et al., 2018, and for examples on the use of GMDI see Câmara et al., 2019; Oliveira et al., 2019, 2021, and Silva et al., 2019, and finally Supplementary Table 1 for specific values at our study sites.

\section{Identification of Species}

We split the field recordings into 5-s segments, totaling 60,674 segments $(5,056 \mathrm{~min}$ of bat activity from total of $24,060 \mathrm{~min}$ of recordings from total of 100 recording nights), utilizing the noise filter in Kaleidoscope Lite (version 5.0.3) (Wildlife Acoustics). We analyzed the segments using the Animal Sound Identifier (ASI; Ovaskainen et al., 2018). Initially, we identified which bat taxa existed in our data by running the Cluster Analysis of Kaleidoscope Pro and manually going through a subset of the files until we had reasonable assurance that all or most of the bat sonotypes in our data were found and manually identified with Acoustic Identification Key of Brazilian bats (Arias-Aguilar et al., 2018). It was possible to assign twelve sonotypes to species-level within our dataset. However, because many sonotypes cannot be identified to the species-level, the rest of our bat sonotypes
$(N=6)$ had to be classified to higher taxon-levels (comprising potentially several species with similar calls; see Table 1). Then, utilizing the ASI pipeline (Ovaskainen et al., 2018), we classified all the segments for the presence-absences of the vocalizations of the identified taxa. ASI is a MATLAB software based on machine learning that performs probabilistic classification of species occurrences from field recordings. Training data is generated automatically from field data and therefore there is no need for pre-defined reference libraries, and the quality of training data and field data are exactly the same. We converted the probabilities into sonotype occurrences using the 90\% threshold, which we selected as a conservative strategy to avoid false positives (Figure 2). The resulting matrix shows the relative activity of each sonotype based on their occurrences in each audio file segment (see Table 1 and Supplementary Table 1 for the summary of sonotype occurrences). Although the identification of species and higher taxonomic units was based on the sonotypes classified in the data, hereafter we use species names and taxonomic units in the following sections to better highlight the biological relevance of the results. 
TABLE 1 | Relative activity of all bat sonotypes that were found and identified using Animal Sound Identifier (ASI) with 90\% threshold in Catimbau National Park, Pernambuco, Brazil.

\begin{tabular}{|c|c|c|}
\hline Family & Species/taxon & Total relative activity \\
\hline \multirow[t]{3}{*}{ Emballonuridae } & Peropteryx macrotis & 125 \\
\hline & Peropteryx trinitatis & 1 \\
\hline & Peropteryx sp. * & 15 \\
\hline \multirow[t]{8}{*}{ Molossidae } & Eumops cf. perotis & 10814 \\
\hline & Eumops sp. ${ }^{\star \star}$ & 6740 \\
\hline & Molossus currentium & 472 \\
\hline & Molossus molossus & 71 \\
\hline & Molossus rufus & 1 \\
\hline & Molossidae sp. ${ }^{* \star}$ & 172 \\
\hline & Neoplatymops mattogrossensis & 20 \\
\hline & Promops nasutus & 27 \\
\hline \multirow[t]{2}{*}{ Mormoopidae } & Pteronotus gymnonotus & 344 \\
\hline & Pteronotus personatus & 11 \\
\hline Noctilionidae & Noctilio leporinus & 24 \\
\hline \multirow[t]{3}{*}{ Vespertilionidae } & Eptesicus furinalis & 8 \\
\hline & Lasiurus sp. & 13 \\
\hline & Myotis sp. & 362 \\
\hline Phyllostomidae & Phyllostomidae sp. & 61 \\
\hline
\end{tabular}

*Peropteryx species with frequency of maximum energy (FME) between 41-42 kHz. ${ }^{* *}$ Eumops species with FME close to $18 \mathrm{kHz}$ and always above $15 \mathrm{kHz}$.

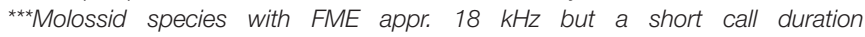
(less than $10 \mathrm{~ms}$ ).

\section{Statistical Analyses}

Animal sound identifier produces a matrix consisting of probabilistic occurrences of identified taxonomic units in each of the audio file segments. We excluded taxa that had less than five occurrences in the data, and thus our analyses consist of $n_{S}=14$ taxonomic units. We define a visit to a study plot as our sampling unit. All study plots were visited three times in total, with each visit consisting of three consecutive nights of recording. Considering four AudioMoth devices were stolen or malfunctioned, the number of visits was $n_{Y}=35$. The number of times that each taxon was recorded to be present for each audio file segment was used as a measure of relative activity, and then the $n_{Y} \mathrm{x} n_{s}$ activity matrix was used as the starting point for the statistical analyses.

We analyzed the data with Hierarchical Modeling of Species Communities (HMSC; Ovaskainen et al., 2017; Ovaskainen and Abrego, 2020). HMSC is a joint species distribution model (Warton et al., 2015) which includes a hierarchical layer modeling how species vary in their responses to environmental covariates (Abrego et al., 2017). As the response variable (the matrix $n_{Y} \times n_{S}$ Y of HMSC; see Ovaskainen et al., 2017), we used the activity matrix. Due to the zero-inflated nature of the data, we applied a hurdle modeling approach, where we fitted one model for presence-absence part of the data and another model for relative activity conditional on presence (henceforth, activity model. Here relative activity conditional on presence means that we excluded cases where the species was not recorded at all by specifying the response variables as missing NA (see Ovaskainen and Abrego, 2020 for more details on hurdle models in the context of HMSC). We applied probit regression for the presence-absence model, and linear regression for the log-transformed activity data for the activity model.

We included as fixed effects (the $n_{y} \times n_{c}$ matrix $\mathbf{X}$ of HMSC, where $n_{c}$ is the number of species-specific regression parameters to be estimated-see (Ovaskainen et al., 2017), the disturbance index GMDI, and the survey time (categorical variable with two classes; September and December). While our primary interest was in the effect of the GMDI, we controlled for survey time for its known influence on bat communities and their activity changing during the season. We further controlled by the study design consisting of repeated visits to the same plots by including plot as a random effect. To identify residual species-to-species cooccurrences, we also included the sampling unit level of the visit as random effect.

We fitted the Hierarchical Modeling of Species Communities (HMSC) model with the R-package Hmsc (Tikhonov et al., 2020) assuming the default prior distributions (Ovaskainen and Abrego, 2020). We sampled the posterior distribution with four

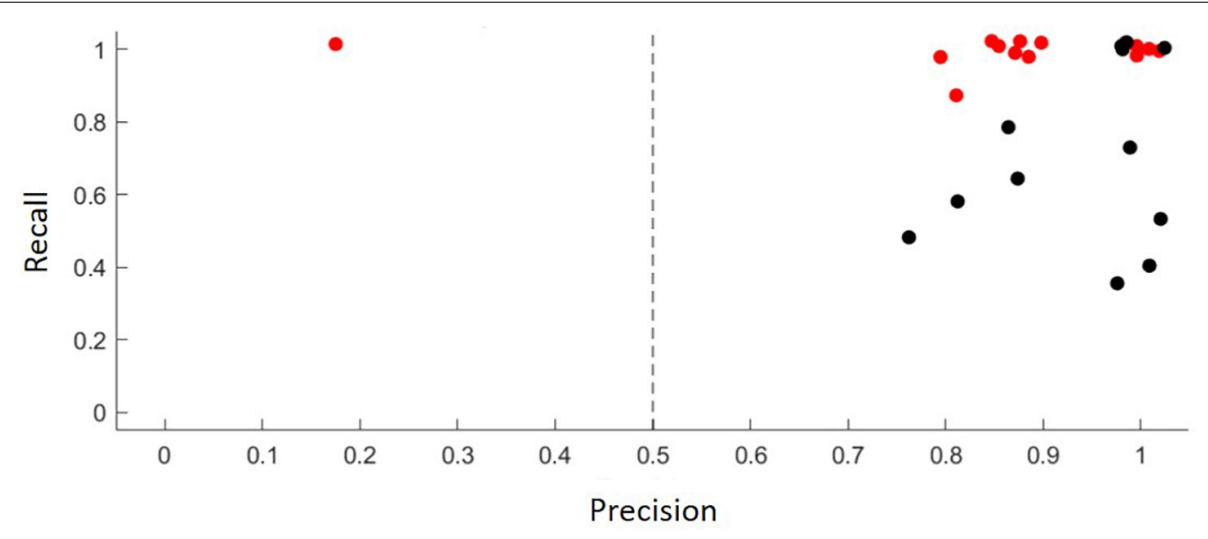

FIGURE 2 | The results of model validation, where the classification probabilities are evaluated against independent validation data in terms of their precision ( $x$; the proportion of classifier hits that are true detections of the target sonotype) and recall (y; the proportion of target sonotype vocalizations that are detected as hits by the classifier), for both of which 1 is the best and 0 the worst value, with colors corresponding to $50 \%$ (red) and $90 \%$ (black) probability thresholds. 
Markov Chain Monte Carlo (MCMC) chains, each of which was run for 375,000 iterations, of which the first 125,000 were removed as burn-in. The chains were thinned by 1,000 to yield 250 posterior samples per chain and so 1,000 posterior samples in total. We examined MCMC convergence by examining the potential scale reduction factors (Gelman and Rubin, 1992) of the model parameters.

We examined the explanatory and predictive powers of the probit model through species-specific AUC (Pearce and Ferrier, 2000) and Tjur's $R^{2}$ (Tjur, 2009) values. The explanatory and predictive powers of the activity model were measured by $\mathrm{R}^{2}$. To compute explanatory power, we made model predictions based on models fitted to all data. To compute predictive power, we performed fivefold cross-validation, in which the sampling units were assigned randomly to fivefold, and predictions for each fold were based on model fitted to data on the remaining fourfold.

To quantify the drivers of community structure, we partitioned the explained variation among the fixed and random effects included in the model. To address our main study question, i.e., if and how human disturbance influences bat communities, we examined species responses to the disturbance index GMDI, counting what proportion of species showed a positive or negative response with at least $75 \%$ posterior probability (which we considered to indicate mild statistical support) or with at least $95 \%$ posterior probability (which we considered to indicate strong statistical support). We further examined the effect of survey time using the same posterior probability thresholds.

\section{RESULTS}

\section{Species Identification}

We observed the presence and activity of 18 bat sonotypes (12 species, five genus-level classifications, and one family-level classification) in the sampled area. A large amount of variation in relative activity was documented between taxa (Table 1). The most dominant taxon (out of 18) was Eumops cf. perotis, covering $56.09 \%$ of all relative activity. The family to which $E$. cf. perotis belongs, Molossidae, is also the most dominant family of all, covering $95.01 \%$ of all relative activity. Other families included in the data were Vespertilionidae ( $1.88 \%$ of the data), Mormoopidae (1.84\% of the data), Emballonuridae $(0.74 \%$ of the data), Phyllostomidae $(0.32 \%$ of the data) and Noctilionidae $(0.12 \%$ of the data).

\section{Model Fitting}

The MCMC convergence of the HMSC models was satisfactory: the potential scale reduction factors for the $\beta$-parameters (that measure the responses of the species to environmental covariates; Ovaskainen et al., 2017) were on average 1.02 (maximum 1.07) for the presence-absence model and 1.06 (maximum 1.12) for the activity model (see Supporting Information for details). The presence-absence model showed a good fit to the data, the mean Tjur $\mathrm{R}^{2}$ (AUC) being on average 0.35 (0.87) for explanatory power and $0.28(0.84)$ for the predictive power. The activity model showed satisfactory model fit, the mean $\mathrm{R}^{2}$ being 0.45 for explanatory power and 0.27 predictive power.

\section{Effect of Human Disturbance}

Variance partitioning over the explanatory variables included in the models showed that the fixed effects explained a substantial amount of variation in the presence-absence model (survey time $=30.2 \%$ and GMDI $=33.1 \%)($ Figure $3 \mathbf{A})$, whereas in the activity model the survey time explained $35.4 \%$ of variation and the human disturbance index GMDI explained 20.2\% (Figure 3B). Accounting only for responses that were positive or negative with at least $95 \%$ posterior probability, in the presence-absence only one of the species (Molossus molossus) showed a positive response to human disturbance index (GMDI) (Figure 4A), whereas in the activity model another taxon (Myotis sp.) showed a negative response to GMDI (Figure 4B). With the lower threshold of $75 \%$, both models showed more responses to the human disturbance. In the presence-absence model, the lower threshold resulted in positive responses to GMDI for Molossus currentium, Molossus molossus, Molossidae, Myotis sp., Peropteryx sp., and Pteronotus gymnonotus. In the activity model Eumops perotis and Eumops sp. showed positive responses to human disturbance index, and Myotis sp., Pteronotus gymnonotus, Peropteryx macrotis and Promops nasutus showed negative responses.

Survey time influenced species relative activity in both presence-absence model and in activity model. In presenceabsence model seven out of 14 taxonomic units had a higher occurrence probability in the December survey time than in the September survey time (Figure 4A), and in the activity model 13 taxonomic units were more active in December survey time (Figure 4B). Only one species, Molossus currentium, was associated negatively to December survey with mild statistical support (posterior probability of 75\%) in the presenceabsence model.

The presence-absence model resulted in a probability of $93 \%$, by which a site with high GMDI has higher species richness than a site with low GMDI. By "high and low GMDI sites", we refer to the highest and lowest values of GMDI among our data (Figure 5A). The activity model gave a corresponding $80 \%$ probability that a high GMDI site has lower relative activity than a low GMDI site, assuming the same bats are present at both sites (Figure 5B).

\section{DISCUSSION}

We investigated the relationship between human disturbance, bat activity and species richness (as measured by sonotype richness in our data) of insectivorous bats considering responses of different taxa at sites under different anthropogenic degrees in Brazil's Caatinga drylands. We found trends in the association of the disturbance gradient with the species richness and relative activity: Species richness was higher at sites with higher human disturbance, whereas relative activity decreased with increasing human disturbance. Additionally, we observed that species responded differently to the degrees of human disturbance. 

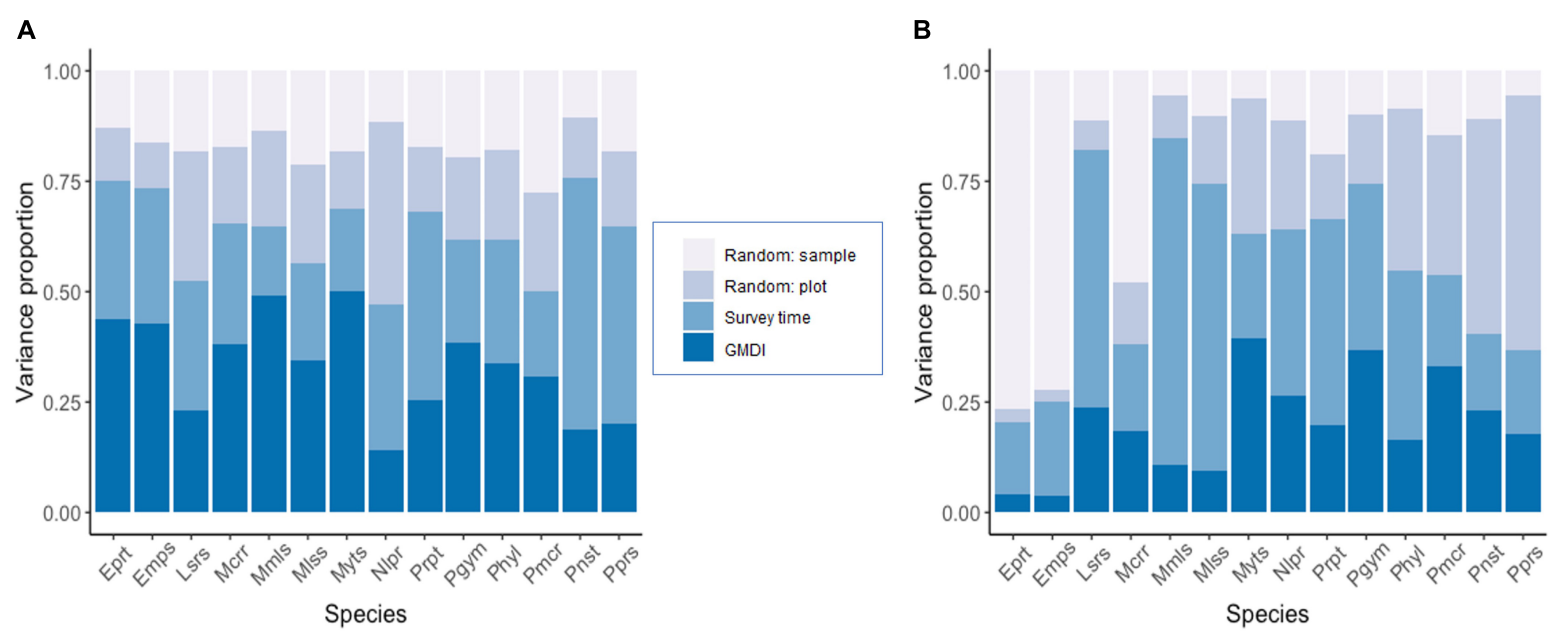

FIGURE 3 | Variance partitioning among the explanatory variables included in the models. Panel (A) shows the results for the presence-absence model and panel (B) for the abundance model for relative activity. The taxonomic units have been ordered alphabetically.

A

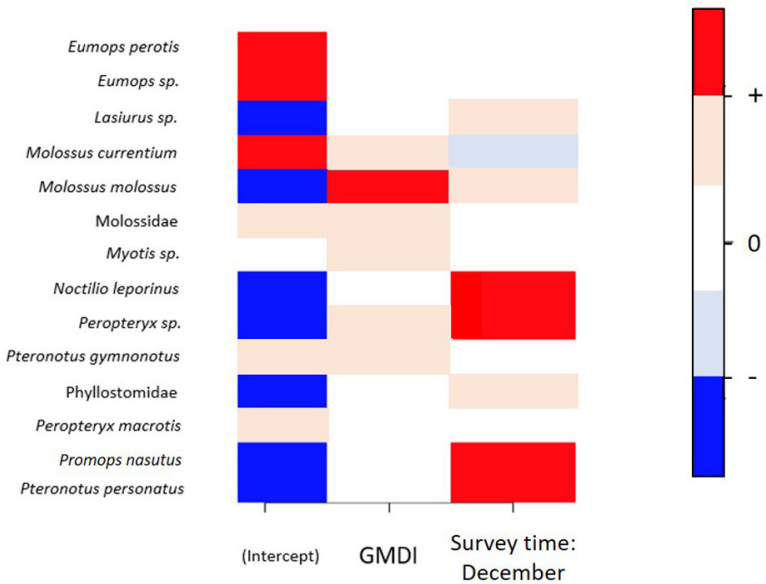

B

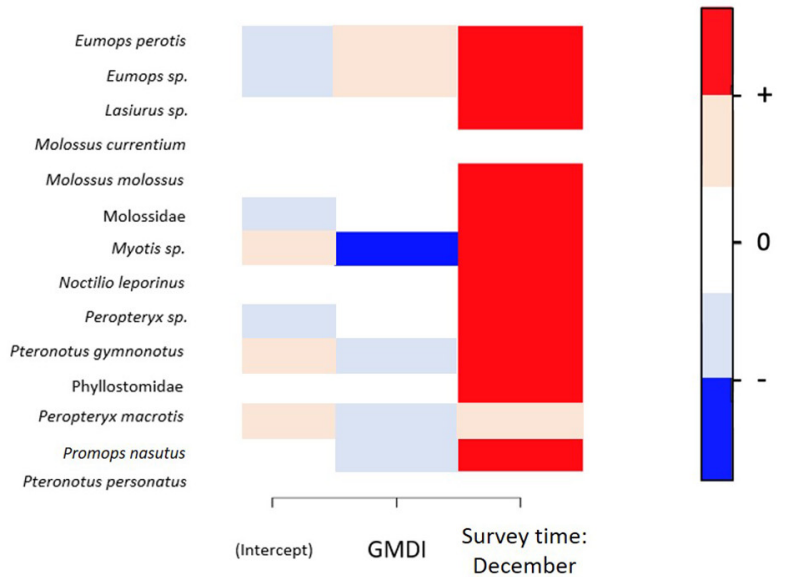

FIGURE 4 | The responses of the bat taxa to environmental covariates. Panel (A) shows the results for the presence-absence model and panel (B) for the abundance model for relative activity. In both panels, positive responses are shown by dark (95\% probability) or light (75\% probability) red, while negative responses are shown by dark (95\%) or light (75\%) blue. Responses that did not gain statistical support at the $75 \%$ level are shown by white.

While Myotis bats (family Vespertilionidae) tended to decrease activity in the most impacted research sites, Molossus molossus (Molossidae) showed an increase, with further responses at the lower threshold on other taxa. We also found differences between the sampling times both in species richness and in relative activity: both of them were higher in December than in September. Finally, our acoustic sampling design was mostly efficient at capturing variation in insectivorous bat activity, whereas it did not allow the analysis of variation in nectarivorous or frugivorous species more often sampled by mist-netting in the tropics (Mancini et al., 2022). Bearing this in mind, we centered discussion around conclusions we can draw from our data on insectivorous species.
Bats are sensitive to human-based habitat changes, but in the literature, results in studies conducted in the Neotropics are inconsistent (García-Morales et al., 2013). Some results indicate a decrease in bat activity as disturbance increases (Fenton et al., 1992; Medellín et al., 2000; Estrada and Coates, 2002), whereas others indicate no effect (Clarke et al., 2005; Pineda et al., 2005), or an opposite outcome, where areas impacted by human activities can actually harbor more bat species than wellpreserved forests (Vargas et al., 2008; García-Morales et al., 2013). Acknowledging methodology used to measure the impacts of disturbance varies between the aforementioned studies, our results concur with the latter. One reason for this could be that human settlements can offer suitable roost sites for a number 


\section{A}

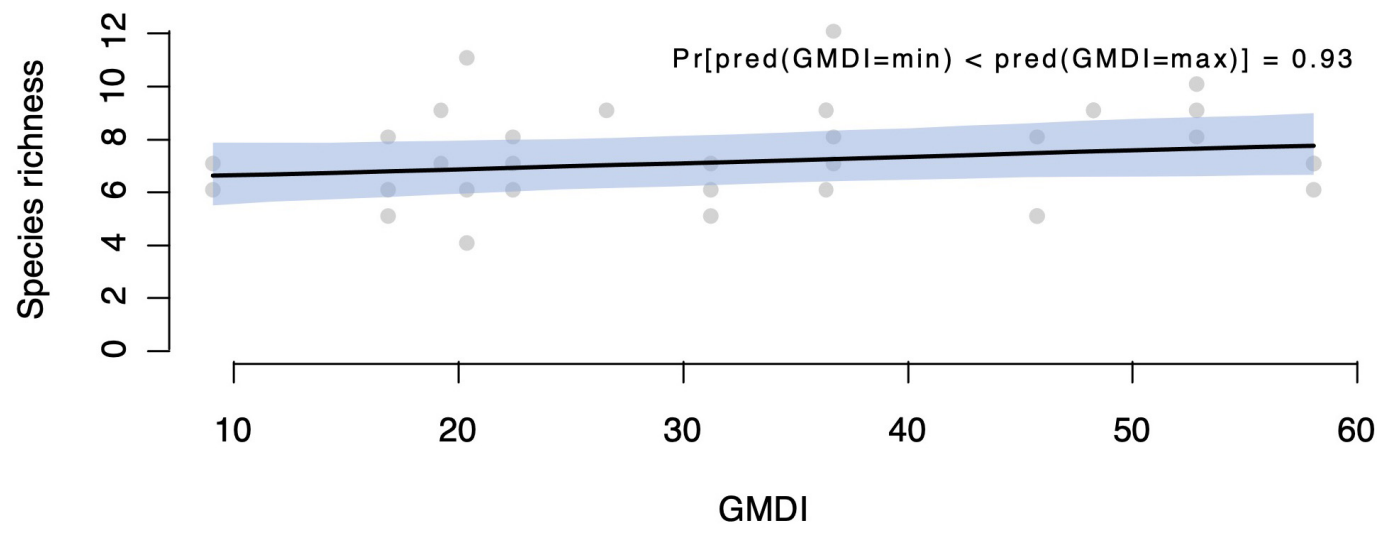

B

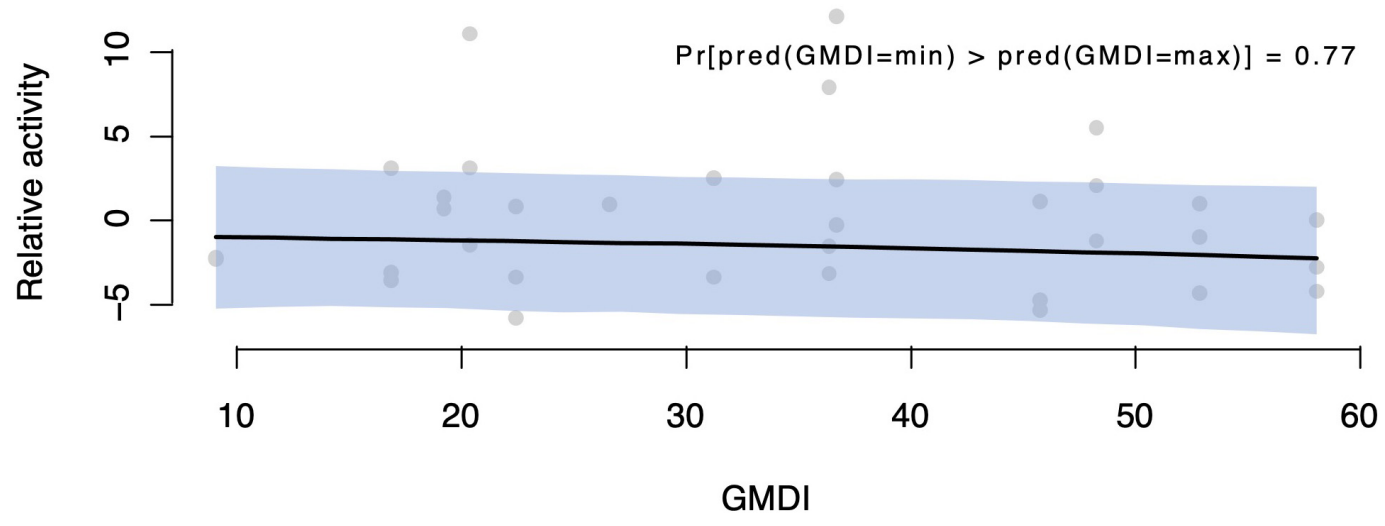

FIGURE 5 | Predicted responses of bat taxa to different disturbance regimes in the Caatinga dry forests of Brazil. Human disturbance was expressed by the GMDI, where higher values indicated more disturbed areas. Sites with higher GMDI had higher species richness [93\% posterior probability-panel (A)], but lower activity [80\% posterior probability - panel (B)].

of insectivorous bat species (especially buildings). This could probably be the case in our study, because some bat genera in our data are known to utilize human structures, such as houses, bridges and towers [e.g., Peropteryx, Molossus, Promops; (Bonaccorso, 2019; Taylor, 2019)]. However, suitable roosting sites may not reside within, or close to, preferred foraging areas. In the present study, bat activity was lower in areas with more human disturbance. Some Neotropical insectivorous species restrict their activity to the vicinity of their roosts but others, such as the Molossids most frequent in our data, can travel long distances between roosts and foraging areas even in fragmented landscape (Bernard and Fenton, 2003). Our data may include recordings of bats leaving their roosts at disturbed sites that flew farther out to forage. This means our results may provide biased information on the areas bat species use and, in this respect, especially presence-absence data presents only general trends on how bats may respond when faced with chronic anthropogenic disturbances. Therefore, both species richness and species activity should be used as measures when studying the impact of human disturbance on bat communities. Additionally, the lack of frugivorous and nectarivorous species in our data suggest (being also consistent with other studies with an acoustic approach, e.g., Jung and Kalko, 2011; Mancini et al., 2022) acoustic sampling does not efficiently capture their activity.

Survey time explained a substantial amount of variation in both models. The region where the study was conducted, the Caatinga, is characterized by an unpredictable and low precipitation regime, generally concentrated into a short, irregular wet season between April and August (Rocha et al., 2015). Thus, three sampling visits (in September and December) were all placed outside of the rainy season, but the differences between the sampling time points were still evident regarding both species richness and activity. Some species were only observed in December and almost all species were also substantially more active in December. The result is somewhat surprising because September is closer to the wet season than December. A previous study on the impact of seasonality on bat communities conducted in Caatinga, bats occurred either the same during the seasons or were more prominent in the number of species and individuals during the wet season than 
in dry season (Rocha et al., 2015). However, Rocha et al. (2015) used a different method (mist netting) and had only a very few insectivores in their data, which was in total contrast to our data. In the Neotropics, aerial insectivorous bats are rarely sampled by harp traps or mist nets (Kalko and Handley, 2001; Mancini et al., 2022). However, the observed differences in bat activity and species richness between sampling time points may represent natural variation in habitat use due to the phenology of their circannual cycle (Vasko et al., 2020), rather than factors attributable to climatic conditions, which did not differ markedly in our data.

Our results suggest that, in Caatinga, insectivorous bats are not particularly sensitive to environmental alteration. However, some patterns emerged when the responses of the different bat groups were assessed separately for human disturbance. At the family-level, there was higher relative activity of Molossidae among plots, and their responses were positively associated with human-used areas. Molossus molossus was positively associated with disturbance index GMDI in the presence-absence model, while other molossid species or taxa (Molossus currentium, Molossidae sp., Eumops perotis, and Eumops sp.; see the Table 1 and Supplementary Table 1) also showed weaker positive associations with human disturbance. In Neotropics, molossids (Molossidae) as a group are not necessarily overly sensitive to human disturbance: they have broad foraging plasticity, their long narrow wings are associated with high flight speed and reduced energy costs of flight, and their echolocation characteristics allow the location of fast-flying prey from a relatively long distance (Rodríguez-Aguilar et al., 2017; Hintze et al., 2020). These ecomorphological traits have favored foraging in open areas or areas with a low percentage of tree cover (Kalko and Handley, 2001; Marinello and Bernard, 2014). So, in the Caatinga drylands, those bats fly high above the vegetation and probably do not interact with the lower habitat layers per se. Habitat altered by humans could affect them by reducing natural roost or prey options. However, molossids are frequently found roosting in man-made structures and are pointed out as species who may have benefited from human development (Jung and Kalko, 2010, 2011; Jung and Threlfall, 2016; Voigt et al., 2016). Also Peropteryx species, that showed a weaker positive response in the presence-absence model (Peropteryx sp.) and a weaker negative response in the activity model for relative activity (Peropteryx macrotis), may use man-made buildings as roosting sites besides the natural ones (Bonaccorso, 2019).

Our data suggested Myotis bats were negatively related to GMDI in the activity model for relative activity. Myotis are characterized by higher flight maneuverability and produce short broadband frequency modulated calls, which enable them to forage in closed spaced areas such as the interior of forests (Marinello and Bernard, 2014). In Europe, studies on a number of Myotis species have indicated this genus to be sensitive to human impact, specifically with regards to habitat selection (Kuijper et al., 2008; Dietz et al., 2020). In urban areas, Myotis have been associated with more preserved and greener areas (Rodríguez-Aguilar et al., 2017). However, some studies have shown that despite selecting for foraging habitat, the roosting behavior does not necessarily show difference between pristine and ruralized areas (Dietz et al., 2020). This is also suggested by our results because although Myotis reacted negatively to human disturbance in the activity model, they still had a slight positive association in the presence-absence model (Figure 4A).

Although we detected different activity patterns among taxonomic groups, overall bat relative activity was not sharply related to chronic human disturbance gradients. This may be related to the maintenance of minimum amounts of vegetation, perceived by bats as adequate for their foraging activities (ÁvilaFlores and Fenton, 2005; Dixon, 2011; García-Morales et al., 2013; Wordley et al., 2017). All of our sampling plots had a minimum of at least $40 \%$ of their natural cover and the highest disturbance index in our study area, based on the GMDI, was $~ 58 \%$. So far, negative correlations between the GMDI and other taxonomic groups have also been observed in the Caatinga region, for example in ant communities (Leal et al., 2014; Oliveira et al., 2017) and in plant communities (Ribeiro et al., 2015, 2016; Zorger et al., 2019), but for some plant species also see: Rito et al., 2017.

Another possibility is that, the degree of disturbance detected by GMDI values alone might not be sensitive enough to explain bat responses to chronic human disturbance. The disturbance index GMDI adopted in the study is a more comprehensive index compared to traditional field measurements as it also considers socio-ecological and geographical approaches. GMDI is particularly relevant to arid and semi-arid areas of developing countries, where people are highly dependent on the extraction of natural resources (Arnan et al., 2018). The unanticipated patterns in our study could differ if each type of human impact were to be evaluated separately. Additionally, other variables, such as plant composition, the existence of different vegetation layers, or even water proximity - all not considered by the GMDImay be useful in such an approach. Bats seem to respond to landscape physiognomy (e.g., fragmentation and edge length) and to a refined scale where habitats and resources are vital (e.g., roosting and water) (Mendes et al., 2017; Rodríguez-Aguilar et al., 2017). For example, on a local scale, prey availability, and weather conditions are the main factors dictating site selection by bats (Mendes et al., 2017). Indeed, some studies have revealed that insectivorous bats can persist in anthropogenic habitats if vital resources such as roosting, foraging, and water are available (Ethier and Fahrig, 2011; Araújo and Bernard, 2015; Mendes et al., 2017; Rodríguez-Aguilar et al., 2017). Some of those vital resources may be available for bats in our study area: we detected feeding buzzes, inferring foraging activity and presence of prey in our study area. However, additional variables will be necessary to explain responses to human impacts in the Caatinga at a refined scale.

The use of acoustic identification of bats as a research tool has increased substantially over the past few decades but in Neotropics, most bat inventories have mostly been conducted using mistnet sampling and roost search (Sampaio et al., 2003; Arias-Aguilar et al., 2018; Pedroso et al., 2020). Bioacoustic methods have been used less due to the lack of high quality reference material (Arias-Aguilar et al., 2018). The use of acoustics has proven to be an effective method for the inventory of insectivorous bats (Murray et al., 1999; Rydell et al., 2002; Silva and Bernard, 2017; Mancini et al., 2022), but for acoustically 
similar or low amplitude species, such as phyllostomid bats, the acoustic approach is rather ineffective (Biscardi et al., 2004; Obrist et al., 2004; Mancini et al., 2022). Even in our study, we partly had to rely on sonotypes, because we could not be sure of speciel-level identifications based on echolocation parameters. All the bat species occurred in our data are primarily insectivores, with the exception of the piscivorous Noctilio leporinus (Wilman et al., 2014). In our acoustic data molossids were clearly the most abundant family responsible for $95 \%$ of all relative activity. They typically forage well above the ground and high-flying bats have turned out well recognizable during commuting or hunting at high altitude, and can be recorded from a relative long distance because their low frequency calls do not attenuate as rapidly as the higher pithed calls of other families (Rodríguez-Aguilar et al., 2017; Arias-Aguilar et al., 2018; Hintze et al., 2020). We suggest this, and their large home ranges, may be one of the reasons why molossids appear to be overrepresented in the data. The abundant occurrence of the Molossidae in bioacoustic datasets, in terms of both abundance and the number of species is not atypical for most Neotropical biomes (Jung and Kalko, 2011; RodríguezAguilar et al., 2017; Hintze et al., 2020). This not only reflects their relative diversity and tolerance to disturbance, but also the comparative effectiveness of bioacoustics in capturing molossid calls (Jung and Kalko, 2010; Ballesteros-Correa and Pérez-Torres, 2022; Mancini et al., 2022). Additionally, the sound analysis program in use (Animal Sound Identifier, ASI; Ovaskainen et al., 2018) is based on machine learning, and therefore the species identification skills of the user also affect the outcome. However, the results of model validation, where the classification probabilities are evaluated against independent validation data in terms of their precision, was deemed satisfactory.

\section{CONCLUSION}

Given the widespread threat to the conservation of the Brazilian Caatinga represented by intensive cultivation and grazing from livestock, the assessment of the effects of anthropogenic changes on the structure of bat assemblages may produce practical results useful for conservation and restoration. It is also worth noticing that of the tropical forests, rainforests have been much more widely studied than dry forests even though approximately $40 \%$ of tropical forests around the world are considered dry (Murphy and Lugo, 1986; Miles et al., 2006). Our study shows that insectivorous Caatinga bat fauna, in general, was not highly affected by the gradient of human disturbance. Our results indicate that species richness is higher at sites with higher human disturbance, while relative activity decreases as human disturbance increases. Additionally, we detected essential species-specific and group-specific responses, with Molossus molossus having a positive response to human disturbance, and Myotis species having a negative response. While represented by relatively few species, the molossids were the predominant group during the whole study periods, specifically in terms of activity, and their responses were largely positively associated with human-used areas. We conclude that the effects of chronic anthropogenic disturbance on the bat fauna in the Caatinga are not homogeneous and that the study of human impacts on this biota will require species-specific approaches. Studies using different methods for bat inventories (specifically mistnet sampling versus bioacoustic inventory) yield results that differ from each other (Mancini et al., 2022). The bioacoustics approach we chose is almost exclusively suitable only for the study of insectivores, and should be complemented with other methods in order to obtain a more complete picture of bat communities.

\section{DATA AVAILABILITY STATEMENT}

The datasets presented in this study can be found in online repositories. The names of the repository/repositories and accession number(s) can be found below: https://github.com/ tmlill/Caatinga_Meramo.git.

\section{AUTHOR CONTRIBUTIONS}

KM, OO, TL, and EB designed the study. KM and CS collected the data. KM and $\mathrm{OO}$ analyzed the data. KM and VL produced visualizations. KM wrote the first draft of the manuscript. All authors contributed to the final version of the manuscript.

\section{FUNDING}

KM was funded by Kone Foundation (grant no. 201800877). OO was funded by Academy of Finland (grant no. 309581), Jane and Aatos Erkko Foundation, Research Council of Norway through its Centers of Excellence Funding Scheme (223257), and the European Research Council (ERC) under the European Union's Horizon 2020 research and innovation program (grant agreement No 856506; ERC-synergy project LIFEPLAN). EB has a research fellowship from CNPq. CS was supported by FACEPE (process IBPG-0756-2.05/17) and financed in part by the Coordenação de Aperfeiçoamento de Pessoal de Nível Superior-Brasil (CAPES) Finance Code 001. TL was funded by Academy of Finland (grant no 3535133).

\section{ACKNOWLEDGMENTS}

We would like to thank the logistical support and authorizations to carry out fieldwork provided by ICMBIO and PELDCatimbau. We would also like to thank Harry Lehto, Frederico Hintze, and Pepper for kindly offering their expertise on acoustical identification of bats and hydration.

\section{SUPPLEMENTARY MATERIAL}

The Supplementary Material for this article can be found online at: https://www.frontiersin.org/articles/10.3389/fevo.2022. 822415/full\#supplementary-material 


\section{REFERENCES}

Abrego, N., Norberg, A., and Ovaskainen, O. (2017). Measuring and predicting the influence of traits on the assembly processes of wood-inhabiting fungi. J. Ecol. 105, 1070-1081. doi: 10.1111/1365-2745.12722

Aguiar, L. M. S., Bueno-Rocha, I. D., Oliveira, G., Pires, E. S., Vasconcelos, S., Nunes, G. L., et al. (2021). Going out for dinner-The consumption of agriculture pests by bats in urban areas. PLoS One 16:e0258066. doi: 10.1371/ journal.pone. 0258066

Aizpurua, O., Budinski, I., Georgiakakis, P., Gopalakrishnan, S., Ibañez, C., Mata, V., et al. (2018). Agriculture shapes the trophic niche of a bat preying on multiple pest arthropods across Europe: evidence from DNA metabarcoding. Mol. Ecol. 27, 815-825. doi: 10.1111/mec.14474

Araújo, M., and Bernard, E. (2015). Green remnants are hotspots for bat activity in a large Brazilian urban area. Urban Ecosyst. 19, 287-296. doi: 10.1007/s11252015-0487-z

Arias-Aguilar, A., Hintze, F., Aguiar, L., Rufray, V., Bernard, E., and Ramos Pereira, M. J. (2018). Who's calling? Acoustic identification of Brazilian bats. Mammal Res. 63, 231-253. doi: 10.1007/s13364-018-0367-z

Arnan, X., Leal, I. R., Tabarelli, M., Andrade, J. F., Barros, M. F., Câmara, T., et al. (2018). A framework for deriving measures of chronic anthropogenic disturbance: surrogate, direct, single and multi-metric indices in Brazilian Caatinga. Ecol. Indic. 94, 274-282. doi: 10.1016/j.ecolind.2018.07.001

Ávila-Flores, R., and Fenton, M. B. (2005). Use of Spatial Features by Foraging Insectivorous Bats in a Large Urban Landscape. J. Mammal. 86, 1193-1204. doi: 10.1644/04-MAMM-A-085R1.1

Ballesteros-Correa, J., and Pérez-Torres, J. (2022). Silvopastoral and conventional management of extensive livestock and the diversity of bats in fragments of tropical dry forest in Córdoba, Colombia. Agrofor. Syst. 2022:391.

Bernard, E., and Fenton, B. (2003). Bat Mobility and Roosts in a Fragmented Landscape in Central Amazonia, Brazil. Biotropica 35, 262-277. doi: 10.1111/ j.1744-7429.2003.tb00285.x

Bernard, E., and Fenton, M. B. (2002). Species diversity of bats (Mammalia: Chiroptera) in forest fragments, primary forests, and savannas in central Amazonia. Brazil. Can. J. Zool. 80, 1124-1140. doi: 10.1139/z02-094

Biscardi, S., Orprecio, J., Fenton, B., Tsoar, A., and Ratcliffe, J. (2004). Data, Sample Sizes and Statistics Affect the Recognition of Species of Bats by Their Echolocation Calls. Acta Chiropterol. 6, 347-363. doi: 10.3161/ 1508110042955513

Bonaccorso, F. J. (2019). “Family Emballonuridae (Sheat-tailed Bats)," in Handbook of the Mammals of the World, eds D. E. Wilson., R. A. Mittermeier. (Spain: Lynx Edicions), 9. 334-373.

Câmara, T., Leal, I. R., Blüthgen, N., Oliveira, F. M. P., and Arnan, X. (2019). Anthropogenic disturbance and rainfall variation threaten the stability of plantant interactions in the Brazilian Caatinga. Ecography 42, 1960-1972. doi: 10. 1111/ecog.04531

Cavalcanti, L. C. D. S., and Corrêa, A. (2014). Pluviosidade no Parque Nacional do Catimbau (Pernambuco): seus Condicionantes e seus Efeitos sobre a Paisagem. Geografia 23, 133-156. doi: 10.5433/2447-1747.2014V23N2P133

Clarke, F., Pio, D., and Racey, P. (2005). A Comparison of Logging Systems and Bat Diversity in the Neotropics. Conserv. Biol. 19, 1194-1204. doi: 10.1111/j.15231739.2005.00086.x-i1

Cordero-Schmidt, E., Maruyama, P. K., Vargas-Mena, J. C., Pereira Oliveira, P., de Assis, R., Santos, F., et al. (2021). Bat-flower interaction networks in Caatinga reveal generalized associations and temporal stability. Biotropica 53, 1546-1557. doi: 10.1111/btp.13007

de la Peña-Cuéllar, E., Benítez-Malvido, J., Avila-Cabadilla, L. D., MartínezRamos, M., and Estrada, A. (2015). Structure and diversity of phyllostomid bat assemblages on riparian corridors in a human-dominated tropical landscape. Ecol. Evol. 5, 903-913. doi: 10.1002/ece3.1375

Delgado-Jaramillo, M., Barbier, E., and Bernard, E. (2018). New records, potential distribution, and conservation of the Near Threatened cave bat Natalus macrourus in Brazil. Oryx 52, 579-586. doi: 10.1017/S003060531600 1186

Dietz, M., Bögelsack, K., Krannich, A., and Simon, O. (2020). Woodland fragments in urban landscapes are important bat areas: an example of the endangered Bechstein's bat Myotis bechsteinii. Urban Ecosyst. 23, 1359-1370. doi: 10.1007/ s11252-020-01008-z
Dixon, M. (2011). Relationship between land cover and insectivorous bat activity in an urban landscape. Urban Ecosyst. 15, 683-695. doi: 10.1007/s11252-0110219-y

Drechsler-Santos, E., Santos, P., Gibertoni, T., and Cavalcanti, M. (2010). Ecological aspects of Hymenochaetaceae in an area of Caatinga (semi-arid) in Northeast Brazil. Fungal Divers. 42, 71-78. doi: 10.1007/s13225-010-0021-9

Ellis, E. C., and Ramankutty, N. (2008). Putting people in the map: anthropogenic biomes of the world. Front. Ecol. Environ. 6:439-447. doi: 10.1890/070062

Estrada, A., and Coates, R. (2002). Bats in continuous forest, forest fragments and in an agricultural mosaic habitat-island at Los Tuxtlas, Mexico. Biol. Conserv. 103, 237-245. doi: 10.1016/S0006-3207(01)00135-5

Estrada-Villegas, S., Mcgill, B. J., and Kalko, E. K. V. (2012). Climate, habitat, and species interactions at different scales determine the structure of a Neotropical bat community. Ecology 93, 1183-1193. doi: 10.1890/11-0275.1

Ethier, K., and Fahrig, L. (2011). Positive effects of forest fragmentation, independent of forest amount, on bat abundance in eastern Ontario, Canada. Landsc. Ecol. 26, 865-876. doi: 10.1007/s10980-011-9614-2

Fenton, M. B., Acharya, L., Audet, D., Hickey, M. B. C., Merriman, C., Obrist, M. K., et al. (1992). Phyllostomid Bats (Chiroptera: Phyllostomidae) as Indicators of Habitat Disruption in the Neotropics. Biotropica 24, 440-446. doi: 10.2307/ 2388615

Frick, W., Kingston, T., and Flanders, J. (2019). A review of the major threats and challenges to global bat conservation. Ann. N. Y. Acad. Sci. 1469, 5-25. doi: $10.1111 /$ nyas. 14045

García-Morales, R., Badano, E., and Moreno, C. (2013). Response of Neotropical Bat Assemblages to Human Land Use. Conserv. Biol. 27, 1096-1106. doi: 10. 1111/cobi.12099

Garda, A. A., Lion, M. B., Lima, S. M., de, Q., Mesquita, D. O., Araujo, H. F. P., et al. (2018). Os animais vertebrados do Bioma Caatinga. Ciênc. E Cult. 70, 29-34. doi: 10.21800/2317-66602018000400010

Geise, L., Paresque, R., Sebastião, H., Shirai, L., Astúa, D., and Marroig, G. (2010). Non-volant mammals, Parque Nacional do Catimbau, Vale do Catimbau, Buíque, state of Pernambuco, Brazil, with karyologic data. Check List 6, 180 186. doi: $10.15560 / 6.1 .180$

Gelman, A., and Rubin, D. B. (1992). Inference from Iterative Simulation Using Multiple Sequences. Stat. Sci. 7, 457-472. doi: 10.1214/ss/1177011136

World Wide Fund for Nature [WWF] (2018). "Living Planet Report 2018". in Aiming Higher, eds M. Grooten., R. E. A. Almond (Switzerland: World Wide Fund for Nature).

Hintze, F., Arias-Aguilar, A., Dias-Silva, L., Delgado-Jaramillo, M., Silva, C. R., Jucá, T., et al. (2020). Molossid unlimited: extraordinary extension of range and unusual vocalization patterns of the bat, Promops centralis. J. Mammal. 101, 417-432. doi: 10.1093/jmammal/gyz167

Jones, G., Jacobs, D., Kunz, T., and Racey, P. (2009). Carpe noctem: the importance of bats as bioindicators. Endanger. Species Res. 8, 93-115. doi: $10.3354 /$ esr00182

Jung, K., and Kalko, E. (2010). Where Forest Meets Urbanization: foraging Plasticity of Aerial Insectivorous Bats in an Anthropogenically Altered Environment. J. Mammal. 91, 144-153. doi: 10.1644/08-MAMM-A-313R.1

Jung, K., and Kalko, E. K. V. (2011). Adaptability and vulnerability of high flying Neotropical aerial insectivorous bats to urbanization. Divers. Distrib. 17, 262-274. doi: 10.1111/j.1472-4642.2010.00738.x

Jung, K., and Threlfall, C. G. (2016). "Urbanisation and Its Effects on BatsA Global Meta-Analysis," in Bats in the Anthropocene: Conservation of Bats in a Changing World, eds C. C. Voigt and T. Kingston (Cham: Springer International Publishing), 13-33. doi: 10.1007/978-3-319-25220-9_2

Kalko, E. K. V., and Handley, C. O. (2001). Neotropical bats in the canopy: diversity, community structure, and implications for conservation. Plant Ecol. 153, 319-333. doi: 10.1023/A:1017590007861

Kaufman, D. M. (1995). Diversity of New World Mammals: Universality of the Latitudinal Gradients of Species and Bauplans. J. Mammal. 76, 322-334. doi: $10.2307 / 1382344$

Kuijper, D. P. J., Schut, J., Dullemen, D., Limpens, H., Toorman, H., Goossens, N., et al. (2008). Experimental evidence of light disturbance along commuting routes of Pond bats Myotis dasycneme. Lutra 51, 37-49.

Leal, L. C., Andersen, A. N., and Leal, I. R. (2014). Anthropogenic disturbance reduces seed-dispersal services for myrmecochorous plants in the Brazilian Caatinga. Oecologia 174, 173-181. doi: 10.1007/s00442-013-2740-6 
Mancini, M. C. S., Hintze, F., de Souza Laurindo, R., de Macêdo Mello, R., and Gregorin, R. (2022). Tradition vs. innovation: comparing bioacoustics and mistnet results to bat sampling. Bioacoustics [preprint]. doi: 10.1080/09524622.2021. 2008494

Marinello, M. M., and Bernard, E. (2014). Wing morphology of Neotropical bats: a quantitative and qualitative analysis with implications for habitat use. Can. J. Zool. 92, 141-147. doi: 10.1139/cjz-2013-0127

Maslo, B., Mau, R. L., Kerwin, K., McDonough, R., McHale, E., and Foster, J. T. (2022). Bats provide a critical ecosystem service by consuming a large diversity of agricultural pest insects. Agric. Ecosyst. Environ. 324:107722. doi: 10.1016/j. agee.2021.107722

Mckinney, M. (2009). Urbanization, Biodiversity, and Conservation. BioScience 52, 883-890.

Medellín, R., Equihua, M., and Amin, M. (2000). Bat Diversity and Abundance as Indicators of Disturbance in Neotropical Rainforests. Conserv. Biol. 14, 1666-1675. doi: 10.1111/j.1523-1739.2000.99068.x

Mendes, E. S., Fonseca, C., Marques, S. F., Maia, D., and Ramos Pereira, M. J. (2017). Bat richness and activity in heterogeneous landscapes: guild-specific and scale-dependent? Landsc. Ecol. 32, 295-311. doi: 10.1007/s10980-016-0444-0

Meyer, C., and Kalko, E. (2008). Assemblage-level responses of phyllostomid bats to tropical forest fragmentation: lAND-bridge islands as a model system. J. Biogeogr. 35, 1711-1726. doi: 10.1111/j.1365-2699.2008.01916.x

Meyer, C., Struebig, M., and Willig, M. (2016). "Responses of Tropical Bats to Habitat Fragmentation, Logging, and Deforestation," in Bats in the Anthropocene: Conservation of Bats in a Changing World, eds C. C. Voigt and T. Kingston (Springer: Springer International Publishing), 63-103. doi: 10.1007/978-3-319-25220-9_4

Mickleburgh, S. P., Hutson, A. M., and Racey, P. A. (2002). A review of the global conservation status of bats. Oryx 36, 18-34. doi: 10.1017/S0030605302000054

Miles, L., Newton, A. C., DeFries, R. S., Ravilious, C., May, I., Blyth, S., et al. (2006) A global overview of the conservation status of tropical dry forests. J. Biogeogr. 33, 491-505. doi: 10.1111/j.1365-2699.2005.01424.x

Murphy, P. G., and Lugo, A. E. (1986). Ecology of tropical dry forest. Annu. Rev. Ecol. Syst. 17, 67-88. doi: 10.1146/annurev.es.17.110186.000435

Murray, K., Britzke, E., Hadley, B., and Robbins, L. (1999). Surveying bat communities: a comparison between mist nets and the Anabat II bat detector system. Acta Chiropterol. 1, 105-112.

Núñez, S. F., López-Baucells, A., Rocha, R., Farneda, F. Z., Bobrowiec, P. E. D., Palmeirim, J. M., et al. (2019). Echolocation and Stratum Preference: Key Trait Correlates of Vulnerability of Insectivorous Bats to Tropical Forest Fragmentation. Front. Ecol. Evol. 7:373. doi: 10.3389/fevo.2019.00373

Obrist, M., Boesch, R., and Flückiger, P. (2004). Variability in echolocation call design of 26 Swiss bat species: consequences, limits and options for automated field identification with a synergetic pattern recognition approach. Mammalia 68, 307-322. doi: 10.1515/mamm.2004.030

Oliveira, F. M. P., Andersen, A. N., Arnan, X., Ribeiro-Neto, J. D., Arcoverde, G. B., and Leal, I. R. (2019). Effects of increasing aridity and chronic anthropogenic disturbance on seed dispersal by ants in Brazilian Caatinga. J. Anim. Ecol. 88, 870-880. doi: 10.1111/1365-2656.12979

Oliveira, F. M. P., Ribeiro-Neto, J. D., Andersen, A. N., and Leal, I. R. (2017) Chronic anthropogenic disturbance as a secondary driver of ant community structure: interactions with soil type in Brazilian Caatinga. Environ. Conserv. 44, 115-123. doi: 10.1017/S0376892916000291

Oliveira, F. M. P., Silva, L. L., Leal, I. R., and Arnan, X. (2021). Morphology of four common and phylogenetically distant ant species varies along disturbance and aridity gradients in the Caatinga dry forest. Biotropica 54, 78-90. doi: 10.1111/btp. 13029

Otálora-Ardila, A., Torres, J., Barbier, E., Pimentel, N., Leal, E., and Bernard, E. (2020). Thermally-Assisted Monitoring of Bat Abundance in an Exceptional Cave in Brazil's Caatinga Drylands. Acta Chiropterol. 21, 411-423. doi: 10.3161/ 15081109ACC2019.21.2.016

Ovaskainen, O., and Abrego, N. (2020). Joint Species Distribution Modelling: With Applications in R. Cambridge: Cambridge University Press, doi: 10.1017/ 9781108591720

Ovaskainen, O., Camargo, U. M., de, and Somervuo, P. (2018). Animal Sound Identifier (ASI): software for automated identification of vocal animals. Ecol. Lett. 21, 1244-1254. doi: 10.1111/ele.13092
Ovaskainen, O., Tikhonov, G., Norberg, A., Blanchet, F. G., Duan, L., Dunson, D., et al. (2017). How to make more out of community data? A conceptual framework and its implementation as models and software. Ecol. Lett. 20, 561-576. doi: 10.1111/ele.12757

Park, K. J. (2015). Mitigating the impacts of agriculture on biodiversity: bats and their potential role as bioindicators. Mamm. Biol. 80, 191-204. doi: 10.1016/j. mambio.2014.10.004

Pearce, J., and Ferrier, S. (2000). Evaluating the predictive performance of habitat models developed using logistic regression. Ecol. Model. 133, 225-245. doi: 10.1016/S0304-3800(00)00322-7

Pedroso, M. A., Pereira, A. S., Oliveira, H. S., Souza, J. W. S., Caldas, F. L. S., Beltrão-Mendes, R., et al. (2020). Rapid survey of bats (Chiroptera) in the Atlantic Forest in eastern Sergipe, Brazil: unexpected diversity in a fragmented landscape. Neotropical Biol. Conserv. 15, 317-331. doi: 10.3897/neotropical.15. e51821

Pineda, E., Moreno, C., and Escobar, F. (2005). Frog, Bat, and Dung Beetle Diversity in the Cloud Forest and Coffee Agroecosystems of Veracruz, Mexico. Conserv. Biol. 19, 400-410. doi: 10.1111/j.1523-1739.2005.00531.x

Portillo-Quintero, C., Sanchez-Azofeifa, A., Calvo-Alvarado, J., Quesada, M., do Espirito, and Santo, M. M. (2015). The role of tropical dry forests for biodiversity, carbon and water conservation in the neotropics: lessons learned and opportunities for its sustainable management. Reg. Environ. Change 15, 1039-1049. doi: 10.1007/s10113-014-0689-6

Prange, S., Gehrt, S., and Wiggers, E. (2004). Influences of anthropogenic resources on Raccoon. J. Mammal. Procyon lotor, 483-490. doi: 10.1644/BOS- 121

Queiroz, L. P., Cardoso, D., Fernandes, M. F., and Moro, M. F. (2017). Diversity and Evolution of Flowering Plants of the Caatinga Domain, Vol. 40. Caatinga: Springer International Publishing, doi: 10.1007/978-3-319-68339-3_2

Ramírez-Fráncel, L. A., García-Herrera, L. V., Losada-Prado, S., Reinoso-Flórez, G., Sánchez-Hernández, A., Estrada-Villegas, S., et al. (2021). Bats and their vital ecosystem services: a global review. Integr. Zool 17, 2-23.

Ribeiro, E. M. S., Arroyo-Rodríguez, V., Santos, B. A., Tabarelli, M., and Leal, I. R. (2015). Chronic anthropogenic disturbance drives the biological impoverishment of the Brazilian Caatinga vegetation. J. Appl. Ecol. 52, 611-620. doi: 10.1111/1365-2664.12420

Ribeiro, E. M. S., Santos, B. A., Arroyo-Rodríguez, V., Tabarelli, M., Souza, G., and Leal, I. R. (2016). Phylogenetic impoverishment of plant communities following chronic human disturbances in the Brazilian Caatinga. Ecology 97, 1583-1592. doi: 10.1890/15-1122.1

Rito, K. F., Arroyo-Rodríguez, V., Queiroz, R. T., Leal, I. R., and Tabarelli, M. (2017). Precipitation mediates the effect of human disturbance on the Brazilian Caatinga vegetation. J. Ecol. 105, 828-838. doi: 10.1111/1365-2745.12712

Rocha, P., Ruiz-Esparza, J., Ribeiro, A., and Ferrari, S. (2015). Species diversity and seasonal variation in the composition of a bat community in the semi-arid brazilian caatinga. Acta Sci. Biol. Sci. 37, 197-203. doi: 10.4025/actascibiolsci. v37i2.25746

Rodríguez-Aguilar, G., Orozco-Lugo, C. L., Vleut, I., and Vazquez, L.-B. (2017). Influence of urbanization on the occurrence and activity of aerial insectivorous bats. Urban Ecosyst. 20, 477-488. doi: 10.1007/s11252-016-0608-3

Rodríguez-San Pedro, A., Allendes, J. L., Beltrán, C. A., Chaperon, P. N., Saldarriaga-Córdoba, M. M., Silva, A. X., et al. (2020). Quantifying ecological and economic value of pest control services provided by bats in a vineyard landscape of central Chile. Agric. Ecosyst. Environ. 302, 107063. doi: 10.1016/ j.agee.2020.107063

Russo, D., Salinas-Ramos, V. B., Cistrone, L., Smeraldo, S., Bosso, L., and Ancillotto, L. (2021). Do We Need to Use Bats as Bioindicators? Biology 10:693. doi: 10.3390/biology10080693

Rydell, J., Arita, H. T., Santos, M., and Granados, J. (2002). Acoustic identification of insectivorous bats (order Chiroptera) of Yucatan. Mexico. J. Zool. 257, 27-36. doi: 10.1017/S0952836902000626

Sampaio, E., Kalko, E., Bernard, E., and Handley, C. (2003). A Biodiversity Assessment of Bats (Chiroptera) in a Tropical Lowland Rainforest of Central Amazonia, Including Methodological and Conservation Considerations. Stud. Neotropical Fauna Environ. 38, 17-31. doi: 10.1076/snfe.38.1.17.14035

Silva, C., and Bernard, E. (2017). Bioacoustics as an Important Complementary Tool in Bat Inventories in the Caatinga Drylands of Brazil. Acta Chiropterol. 19, 409-418. doi: 10.3161/15081109ACC2017.19.2.017 
Silva, I. L. H., Leal, I. R., Ribeiro-Neto, J. D., and Arnan, X. (2019). Spatiotemporal responses of ant communities across a disturbance gradient: the role of behavioral traits. Insectes Sociaux 66, 623-635. doi: 10.1007/s00040-01900717-9

Silva, J. M., Leal, I., and Tabarelli, M. (2017). Caatinga: The Largest Tropical Dry Forest Region in South America. Switzerland: Springer, doi: 10.1007/978-3-31968339-3

Silva, U., Delgado-Jaramillo, M., Aguiar, L., and Bernard, E. (2018). Species richness, geographic distribution, pressures, and threats to bats in the Caatinga drylands of Brazil. Biol. Conserv. 221, 312-322. doi: 10.1016/j.biocon.2018. 03.028

Stevens, R. D. (2004). Untangling latitudinal richness gradients at higher taxonomic levels: familial perspectives on the diversity of New World bat communities. J. Biogeogr. 31, 665-674. doi: 10.1111/j.1365-2699.2003.01042.x

Taylor, P. J. (2019). "Family Molossidae (Free-tailed Bats)," in Handbook of the Mammals of the World: Bats, eds E. D, Wilson., A. R, Mittermeier (Spain: Lynx Edicions), 9. 598-673.

Tikhonov, G., Opedal, ØH., Abrego, N., Lehikoinen, A., Jonge, M. M. J., Oksanen, J., et al. (2020). Joint species distribution modelling with the $\mathrm{R}-$ package $\mathrm{H}$ msc. Methods Ecol. Evol. 11, 442-447. doi: 10.1111/2041-210X.13345

Tjur, T. (2009). Coefficients of Determination in Logistic Regression ModelsA New Proposal: the Coefficient of Discrimination. Am. Stat. 63, 366-372. doi: 10.1198/tast.2009.08210

Vargas, A., Aguirre, L., Galarza, M., and Gareca León, E. (2008). Ensamble de murciélagos en sitios con diferente grado de perturbación en un bosque montano del Parque Nacional Carrasco, Bolivia. Mastozool. Neotropical 15, 297-308.

Vasko, V., Blomberg, A. S., Vesterinen, E. J., Suominen, K. M., Ruokolainen, L., Brommer, J. E., et al. (2020). Within-season changes in habitat use of forest-dwelling boreal bats. Ecol. Evol. 10, 4164-4174. doi: 10.1002/ece3. 6253

Vesterinen, E. J., Puisto, A. I. E., Blomberg, A. S., and Lilley, T. M. (2018). Table for five, please: dietary partitioning in boreal bats. Ecol. Evol. 8, 10914-10937. doi: $10.1002 /$ ece 3.4559

Villalobos-Chaves, D., and Rodríguez-Herrera, B. (2021). Frugivorous bats promote epizoochoric seed dispersal and seedling survival in a disturbed Neotropical forest. J. Mammal. 102, 1507-1513. doi: 10.1093/jmammal/ gyab114

Voigt, C., and Kingston, T. (eds) (2015). "Bats in the Anthropocene," in Bats in the Anthropocene: Conservation of Bats in a Changing World (New York, NY: Springer International Publishing), 1-9. doi: 10.1007/978-3319-25220-9_1
Voigt, C. C., Phelps, K. L., Aguirre, L. F., Corrie Schoeman, M., Vanitharani, J., and Zubaid, A. (2016). "Bats and Buildings: The Conservation of Synanthropic Bats," in Bats in the Anthropocene: Conservation of Bats in a Changing World, eds C. C. Voigt and T. Kingston (Cham: Springer International Publishing), 427-462. doi: 10.1007/978-3-319-25220-9_14

Wanger, T. C., Darras, K., Bumrungsri, S., Tscharntke, T., and Klein, A.-M. (2014). Bat pest control contributes to food security in Thailand. Biol. Conserv. 171, 220-223. doi: 10.1016/j.biocon.2014.01.030

Warton, D. I., Blanchet, F. G., O’Hara, R. B., Ovaskainen, O., Taskinen, S., Walker, S. C., et al. (2015). So Many Variables: joint Modeling in Community Ecology. Trends Ecol. Evol. 30, 766-779. doi: 10.1016/j.tree.2015.09.007

Welch, J. N., and Beaulieu, J. M. (2018). Predicting Extinction Risk for Data Deficient Bats. Diversity 10:63. doi: 10.3390/d10030063

Wilman, H., Belmaker, J., Simpson, J., Rosa, C., Rivadeneira, M., and Jetz, W. (2014). EltonTraits 1.0: species-level foraging attributes of the world's birds and mammals. Ecology 95, 2027-2027. doi: 10.1890/13-1917.1

Wordley, C. F. R., Sankaran, M., Mudappa, D., and Altringham, J. D. (2017). Bats in the Ghats: agricultural intensification reduces functional diversity and increases trait filtering in a biodiversity hotspot in India. Biol. Conserv. 210, 48-55. doi: 10.1016/j.biocon.2017.03.026

Zorger, B., Tabarelli, M., Queiroz, R., Rosado, B. H. P., and Pinho, B. (2019). Functional organization of woody plant assemblages along precipitation and human disturbance gradients in a seasonally dry tropical forest. Biotropica 51, 838-850. doi: 10.1111/btp.12721

Conflict of Interest: The authors declare that the research was conducted in the absence of any commercial or financial relationships that could be construed as a potential conflict of interest.

Publisher's Note: All claims expressed in this article are solely those of the authors and do not necessarily represent those of their affiliated organizations, or those of the publisher, the editors and the reviewers. Any product that may be evaluated in this article, or claim that may be made by its manufacturer, is not guaranteed or endorsed by the publisher.

Copyright (c) 2022 Meramo, Ovaskainen, Bernard, Silva, Laine and Lilley. This is an open-access article distributed under the terms of the Creative Commons Attribution License (CC BY). The use, distribution or reproduction in other forums is permitted, provided the original author(s) and the copyright owner(s) are credited and that the original publication in this journal is cited, in accordance with accepted academic practice. No use, distribution or reproduction is permitted which does not comply with these terms. 